\title{
Endothelial-Platelet Dysfunction as an Indicator of Pre-Eclampsia and its Severity
}

\author{
HADER I. SAKR, M.D. ${ }^{1},{ }^{2} ;$ AKEF A. KHOWAILED, M.D. ${ }^{1}$; MOATAZ M. KAMEL, M.D. ${ }^{3}$; \\ MAHA E. FARGHALY, M.Sc. ${ }^{4}$ and EMAN Z. FARID, M.D. ${ }^{5}$ \\ The Department of Physiology, Faculty of Medicine, Cairo University, Egypt ${ }^{1}$ \\ The Department of Physiology, Batterjee Medical College, Jeddah, Saudi Arabia ${ }^{2}$, \\ The Department of Biochemistry Faculty of Medicine, Cairo University, Egypt \\ The Departments of Physiology and Obstetrics \& Gynecology , Faculty of Medicine, Beni-Suef University, Egypt
}

\begin{abstract}
Background: Pre-Eclampsia (PE) is a common, pregnancyspecific syndrome defined by clinical findings of elevated blood pressure combined with proteinuria and edema. It affects 2-8\% of pregnancies worldwide. Hypertensive disorders (including pre-eclampsia) are one of the most common causes of death during pregnancy. It also increases the risk of poor outcomes for both the mother and the baby. It is characterized by a generalized dysfunction of the maternal endothelium, as demonstrated by the increased levels of factor VIII, total and cellular Fibronectin (FN), thrombomodulin, endothelin. Endothelial-platelet dysfunction new concept shows a vital role of endothelial cell and platelet: Endothelial dysfunction, increased vascular reactivity and platelet activation.
\end{abstract}

Aim of Study: The present study was designed to evaluate the value of serum fibronectin and Von Willebrand Factor (VWF) as indicators of endothelial and platelet dysfunction in pre-eclampsia and its severity.

Patients and Methods: The study was done on 50 pregnant women divided into 2 groups with 25 patients in each group. The levels of FN, VWF were measured by ELISA and Platelet Count (PLT) was measured by an automated cell counter.

Results: The level of both FN and VWF were significantly higher while PLT count was significantly lower in cases group compared to the control group. Also, the level of FN was significantly higher in cases of severe pre-eclampsia compared to cases of mild pre-eclampsia.

Conclusion: Endothelial-platelet dysfunction may explain the pathogenesis of pre-eclampsia. FN, VWF level and PLT count may be used as a marker of endothelial and platelet dysfunction in pre-eclampsia and may play a role in confirming the diagnosis. FN level may be also used to differentiate between mild and severe pre-eclampsia.

Key Words: Pre-eclampsia-Endothelial -platelet dysfunction - Fibronectin - Von Willebrand Factor.

\section{Introduction}

PRE-ECLAMPSIA is the development of hypertension and proteinuria in young pregnant women after their 20 weeks of gestation [1]. It affects $2 \%$ $8 \%$ child-bearing women [2] more frequently during their first pregnancy with increasing severity in subsequent pregnancies [3]. It is associated with other symptoms and signs including edema, visual disturbance, headache, and epigastric pain, among others. Preeclampsia is one of the major causes of perinatal morbidity and mortality [1]. Complications of pre-eclampsia include development into eclampsia, HELLP syndrome (hemolysis, elevated liver enzymes, and low platelet count), stroke, and irreversible hepato-renal damage [4]. Pre-eclampsia is also associated with increased frequencies of caesarian sections and preterm deliveries. Fetal complications include intra-uterine fetal growth restriction as well as a higher rate of perinatal fetal deaths [5]. The American Society of Gynecology and Obstetrics (ASGO) recognized two types of pre-eclampsia; mild and severe, based on clinical assessment of frequency and intensity of some aforementioned symptoms and signs [6].

Assessment of risk factors for PE should be a part of routine antenatal care. Women who have identified risk factors may benefit from closer surveillance during pregnancy [7]. Some of the risk factors predisposing to preeclampsia include preexisting hypertension, chronic kidney disease, insulin-dependent diabetics, as well as a prior history of preeclampsia [8]

Some reports in literature documented measurement of biomarkers implicated in the pathophysiology of pre-eclampsia is an effective and reliable method of stratifying pregnant women. Some of 
those biomarkers were related to placental perfusion/vascular resistance (platelet angiotensin-1 1 and renin), others were related to endothelial dysfunction/oxidative stress (platelet activation marker, endothelial adhesion molecules eCAMs) and the third group of markers was related to fetal-placental unit endocrine dysfunction (estriol, inhibin A, corticotropin-releasing hormone), among others [9]. Most of these groups mainly rely on endothelial dysfunction as a measurable risk factor associated with pre-eclampsia. This endothelial dysfunction creates an imbalance between pro and antithrombogenic milieu and disturbance of some immune modulators [10]. Some authors had shown increased levels of endothelial activation biomarkers including thrombomodulin, VWF, FN as well as increased expression of some cell adhesion molecules such as PCAM-1, ICAM-1, and VCAM1 in the plasma of women with pre-eclampsia [11,12]

FN-derived from the Latin word fibra, meaning fiber, and nectere, meaning to bind [13]-is a highmolecular-weight $(\sim 440 \mathrm{kDa})$ glycoprotein found in the extracellular matrix and in blood plasma. It is a heterodimer; its subunits vary in size between 235-270kDa (due to alternative splicing). The secreted FN dimer is a soluble protein which polymerizes to higher order fibrils in the ECM. FN plays a major role in cell adhesion, growth, migration, actin dynamics and differentiation. It plays an important role in many processes such as wound healing and embryonic development. Many of these functions are mediated through fibronectin binding to integrin receptor proteins [14]. Altered FN expression, degradation, and organization have been associated with a number of pathologies, including cancer and fibrosis [15]

In this work, we analyzed the diagnostic value of serum FN level and VWF as indicators of endothelial and platelet dysfunction in PE. This work also aimed at studying the role of both serum FN level and VWF in the process of differentiation between mild and severe cases of PE.

\section{Patients and Methods}

\section{Study group:}

This study was done on 50 pregnant women aged from 18 to 35 years old from the Inpatient Unit of Obstetrics and Gynecology Department, Beni-Suef University Hospital from June - Nov. 2016. After enrollment, participants were divided into two groups into:

1- Control group: Included 25 healthy pregnant women (control group).
2- Pre eclampsia group: Included 25 women that have been diagnosed complaining of PE (study group), 15 of which were suffering from mild $\mathrm{PE}$ and 10 were suffering from severe PE.

\section{Inclusion criteria:}

A- Singleton pregnancy.

B- Gestational age 20 weeks or more.

C- 18-35 years old women.

D- PE was diagnosed by:

1- Blood pressure $>140 \mathrm{mmHg}$ systolic or $>90$ $\mathrm{mmHg}$ diastolic on two separate readings taken at least four to six hours apart after 20 weeks gestation in an individual with previously normal blood pressure.

2- Essential hypertension beginnings before 20 weeks gestational age. The following criteria were used for diagnosis: An increase in Systolic Blood Pressure (SBP) of $>30 \mathrm{mmHg}$ or an increase in Diastolic Blood Pressure (DBP) of $>15 \mathrm{mmHg}$.

3- Proteinuria $>0.3$ grams $(300 \mathrm{mg})$ or more of protein in a 24-hour urine sample or a spot urinary protein to creatinine ratio $>0.3$ or a urine dipstick reading of $1+$ or greater (dipstick reading should only be used if other quantitative methods are not available) [16]

\section{Exclusion criteria:}

A- Twin or multiple pregnancies.

B- Any evidence of chronic hypertension.

C- Diabetes mellitus/random blood sugar $>140$ $\mathrm{mg} / \mathrm{dl}$.

D- Drugs likely increase blood pressure as corticosteroids.

For all women, the following was done:

A- Verbal and written consent after detailed explanation of procedure.

B- At the first visit, detailed history had been taken including age, menstrual history, symptoms and signs suggestive of endocrine disorders and history of chronic diseases including diabetes mellitus and hypertension.

C- General, abdominal and pelvic examination to exclude other causes of hypertension.

D- Ultrasound to confirm gestational age and viability of fetus. 
All women in the study had done the following investigations:

A- Laboratory investigations:

1- Specific investigations:

- Serum FN level.

- Serum VWF level.

- Platelets count.

2- Routine investigation:

- Complete blood picture.

- Liver function tests (ALT, AST, PT and INR).

- Kidney function tests (urea and creatinine level).

B- Abdominal ultrasound: To detect gestational age.

All laboratory investigation was done by the collection of blood samples while detection of gestational age was done by ultrasound and blood pressure was measured by sphygmomanometer and stethoscope.

- Collection of blood sample and preparation of serum: Plasma clots on standing and the remaining liquid is serum. Centrifugation is used to remove the clot and the resulting supernatant, designated serum, is removed carefully by a Pasteur pipette.

\section{- Serum preparation:}

- Blood was collected by venipuncture.

- Whole blood is collected in a covered test tube.

- The blood is allowed to clot by leaving it undisturbed at room temperature about $24^{\circ}$.

- This usually takes 15-30 minutes.

- The clot is removed by centrifuging at 1,000$2,000 \mathrm{x} g$ for 10 minutes in a refrigerated centrifuge. The resulting supernatant is designated serum.

- Following centrifugation, serum was transferred into a clean polypropylene tube using a Pasteur pipette. While handling, the samples were maintained at $2-8^{\circ} \mathrm{C}$.

- Freeze-thaw cycles should be avoided as this is detrimental to many serum components. Samples which are hemolyzed, icteric or lipemic can invalidate certain tests [17]

- Measurement of serum FN and VWF level:

- Principle: Sandwich-ELISA method. The Microelisa strip plate provided in this kit has been pre-coated with antibodies specific to FN or VWF. Standards and samples were added to the appropriate Microelisa strip plate wells and combined to the specific antibody. Then Horseradish Peroxidase (HRP)-conjugated antibodies specific for FN or VWF were added to each Microelisa strip plate well and incubated. Free components are washed away. The solution of TMB substrate was added to each well. Only those wells that contain FN or VWF and HRP conjugated FN or VWF antibodies will appear blue in color and then turn yellow after the addition of the stop solution. At a wavelength of 450nm, the Optical Density (OD) was measured spectrophotometrically. The OD value was proportional to the concentration of FN or VWF. The concentration of FN or VWF in the samples was calculated by comparing the OD of the samples to the standard curve.

- Sample preparation: After collection of the whole blood, the blood was allowed to clot by leaving it undisturbed at room temperature. This took 10-20 minutes. Centrifugation was used to remove the clot at 2,000-3,000rpm for 20 minutes.

- Standards preparation:Ten wells were set for standards in a Microelisa strip plate. $100 \propto 1$ Standard solution and $50 \propto 1$ Standard dilution buffer were added and mixed well In Wells 1 and 2. From Wells 1 and $2100 \propto 1$ solutions were added in Wells 3 and 4 respectively. This was followed by addition of $50 \propto 1$ Standard Dilution buffer which then was mixed well. From Wells 3 and 4, a $50 \propto 1$ solution was discarded. In Wells 5 and 6, a $50 \propto 1$ solution from Wells 3 and 4 was added respectively. This was followed by addition and proper mixing of $50 \propto 1$ Standard Dilution buffer. A $50 \propto 1$ solution from Wells 5 and 6 was added in Wells 7 and 8, respectively. This was followed by addition and proper mixing of $50 \propto 1$ Standard Dilution buffer. A $50 \propto 1$ solution from Wells 7 and 8 was added in Wells 9 and 10, respectively. This was followed by addition and proper mixing of $50 \propto 1$ Standard Dilution buffer. From Wells 9 and 10, a $50 \propto 1$ solution was discarded. After dilution, the total volumes in all the wells were $50 \propto 1$ and the concentrations were $180 \mathrm{ng} / \mathrm{ml}, 120 \mathrm{ng} / \mathrm{ml}, 60 \mathrm{ng} / \mathrm{ml}, 30 \mathrm{ng} / \mathrm{ml}$ and $15 \mathrm{ng} / \mathrm{ml}$, respectively.

- Calculation of results: Known concentrations of Human Fibronectin FN and VWF Standard and their corresponding reading OD is plotted on the log scale (x-axis) and the log scale (y-axis) respectively. The concentrations of Human FN or VWF in the sample were determined by plotting the sample's O.D. on the Y-axis. Calculation of the original concentration was done by multiplying the dilution factor. 


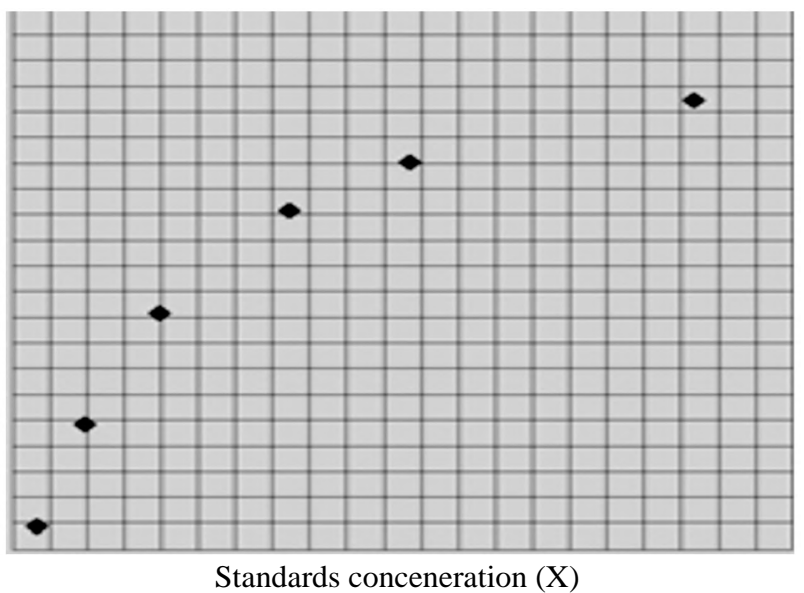

Fig. (1): Standard curve for FN and VWF levels measurement.

- Measurement of Complete Blood Count (CBC): Done by Complete Blood Count with 5-Part Differential [18]

\section{- Measurement of liver function tests (ALT, AST,} $P T$ and INR):

1- Measurement of Alanine Aminotransferase level (ALT): Measured according to Beckman Synchron LX method [19].

2- Measurement of Aspartate Aminotransferase level (AST): Measured according to Beckman UniCel® DxC800 Synchron method [20] .

3- Measurement of Prothrombin Time (PT): Measured according to one stage Prothrombin time method by Quick [21]

- Measurement of kidney function test (creatinine and urea levels): Measured according to Beckman Synchron LX [19].

\section{- Statistical analysis:}

Data were coded and entered using the statistical package SPSS (Statistical Package for the Social Sciences) Version 24. Data was summarized using mean, standard deviation, median, minimum and maximum in quantitative data and using frequency (count) and relative frequency (percentage) for categorical data. Comparisons between quantitative variables were done using the non-parametric Kruskal-Wallis and Mann-Whitney tests [22] . Correlations between quantitative variables were done using Spearman correlation coefficient [23]. Statistically significant $p$-values were those less than 0.05 .

\section{Results}

In the present study, we had 50 patients equally divided into two groups. Each one included 25 patients, the first group was the control group and the second group was PE group.

\section{A- Comparison between the control and PE groups:}

As regard FN level, VWF level, platelets count, AST level and creatinine level, the present study showed a statistically significant difference between pre-eclampsia group and controls (Table 1). PE group showed significantly higher FN and VWF Fig. (2) and significantly lower platelets count Fig. (4A), AST Fig. (5) and creatinine Fig. (6b) levels in comparison with the control group.

In the present study, there was no statistically significant difference between PE group and the control group as regard $\mathrm{Hb}$ level (Table 2) and Fig. (3), WBCs count Fig. (4B), ALT Fig. (5B), urea Fig. (6A) and INR levels Fig. (7).

\section{$B$ - Comparison between mild and severe cases of $P E$ :}

In the present study out of the 25 cases of PE, there were 15 cases suffering from mild PE and 10 cases of severe PE. There was a statistically significant difference between mild and severe PE in the cases group regarding $\mathrm{FN}$ level which was significantly higher in cases of severe PE Fig. (8). However, as regarding VWF level Fig. (8) and platelets count Fig. (9) there was no statistically significant difference between mild and severe PE in the cases group (Table 3 ).

Table (1): Comparison between the control and PE groups regarding FN, VWF, AST and creatinine levels.

\begin{tabular}{lll}
\hline & Control group & \multicolumn{1}{c}{ PE group } \\
\hline Fibronectin level $(\mathrm{ng} / \mathrm{ml})$ & $229.05 \pm 44.66$ & $396.24 \pm 71.03^{*}$ \\
Von Willibrand Factor level $(\mathrm{ng} / \mathrm{ml})$ & $126.68 \pm 24.45$ & $189.46 \pm 24.22^{*}$ \\
Platelets count $\left(10^{3}\right.$ cells/ $\left.\mu \mathrm{l}\right)$ & $250.08 \pm 45.23$ & $181.48 \pm 83.61^{*}$ \\
AST level $(\mathrm{IU} / \mathrm{L})$ & $18.16 \pm 4.15$ & $15.12 \pm 5.65^{*}$ \\
Creatinine level $(\mathrm{mg} / \mathrm{dl})$ & $0.92 \pm 0.12$ & $0.82 \pm 0.16^{*}$ \\
\hline
\end{tabular}

Table (2): Comparison between control group and PE group regarding $\mathrm{Hb}$ level, WBCs count, INR, ALT, and urea levels.

\begin{tabular}{lll}
\hline & $\begin{array}{c}\text { Control } \\
\text { Mean } \pm \text { SD }\end{array}$ & $\begin{array}{c}\text { PE group } \\
\text { Mean } \pm \text { SD }\end{array}$ \\
\hline Hemoglobin level $(\mathrm{gm} / \mathrm{dL})$ & $11.02 \pm 0.94$ & $10.74 \pm 0.96$ \\
WBCs count $\left(10^{3}\right.$ cells/ $\left.\mu \mathrm{L}\right)$ & $9.33 \pm 1.17$ & $8.87 \pm 2.07$ \\
ALT level $(\mathrm{IU} / \mathrm{L})$ & $19 \pm 6.11$ & $15.48 \pm 6.6$ \\
Urea level $(\mathrm{mg} / \mathrm{dL})$ & $24.64 \pm 4.54$ & $24.4 \pm 4.6$ \\
INR level & $1.01 \pm 0.06$ & $1.02 \pm 0.04$ \\
\hline
\end{tabular}

Table (3): Comparison between mild and severe PE cases regarding FN and VWF levels.

\begin{tabular}{lll}
\hline & $\begin{array}{c}\text { Mild PE } \\
\text { Mean } \pm \text { SD }\end{array}$ & $\begin{array}{c}\text { Severe PE } \\
\text { Mean } \pm \text { SD }\end{array}$ \\
\hline Fibronectin level $(\mathrm{ng} / \mathrm{ml})$ & $367.33 \pm 58.62$ & $470.57 \pm 38.6^{*}$ \\
Von Willibrand Factor level $(\mathrm{ng} / \mathrm{ml})$ & $191.48 \pm 27.95$ & $184.28 \pm 9.43$ \\
Platelets count $\left(10^{3}\right.$ cells $\left./ \mu \mathrm{l}\right)$ & $185.44 \pm 38.5$ & $171.29 \pm 39.93$ \\
\hline
\end{tabular}




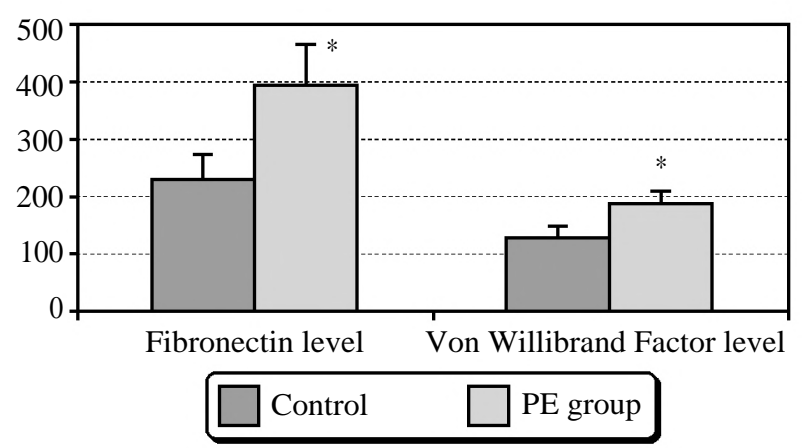

Fig. (2): Comparison between serum FN and VWF levels in the control and PE groups.

Values are mean (in $\mathrm{ng} / \mathrm{ml}) \pm \mathrm{SD}$.

$*$ : Statistically significant differences if $p<0.05$.

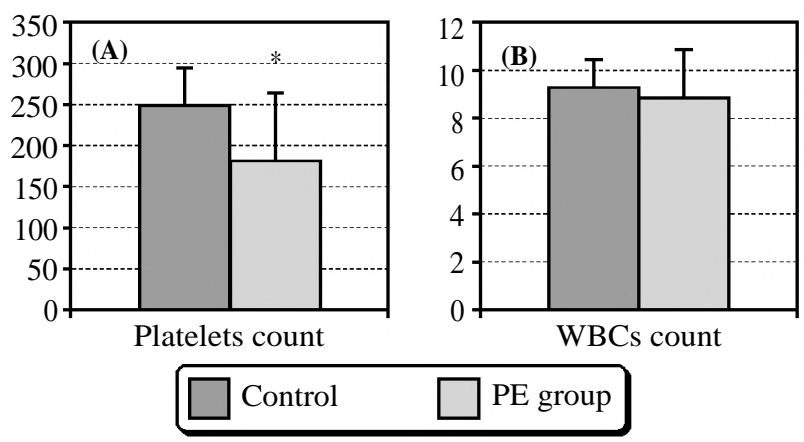

Fig. (4): Comparison between (A) Platelets and (B) WBCs counts in the blood of the control and PE groups.

Values are mean (in $10^{3}$ cells $\left./ \mu \mathrm{l}\right) \pm \mathrm{SD}$.

$*$ : Statistically significant differences if $p<0.05$.

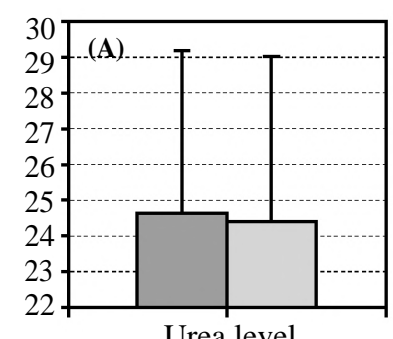

Urea level

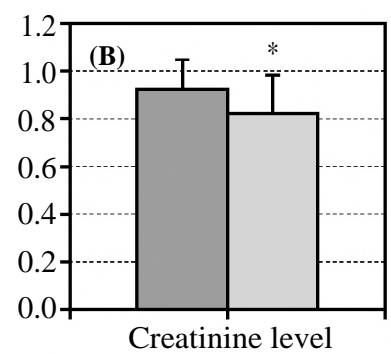

Control

PE group

Fig. (6): Comparison between serum urea (A) and creatinine (B) levels in the control and PE groups.

Values are mean (in $\mathrm{mg} / \mathrm{dL}$ ) $\pm \mathrm{SD}$.

*: Statistically significant differences if $p<0.05$.

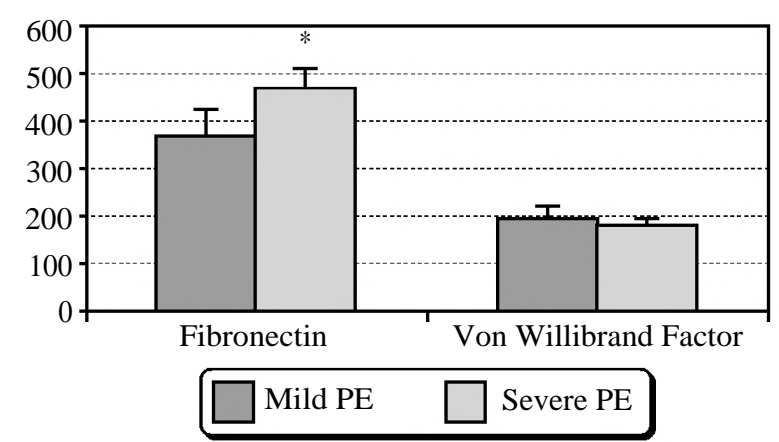

Fig. (8): Comparison between serum FN and VWF levels in mild and severe cases of PE.

Values are mean (in $\mathrm{ng} / \mathrm{ml}) \pm \mathrm{SD}$

$*$ : Statistically significant differences if $p<0.05$.

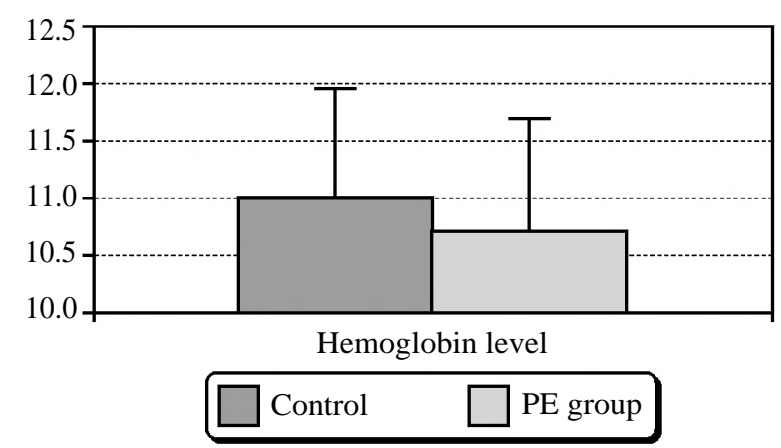

Fig. (3): Comparison between RBCs count in the blood of control and PE groups.

Values are mean (in $\mathrm{gm} / \mathrm{dL}) \pm \mathrm{SD}$.

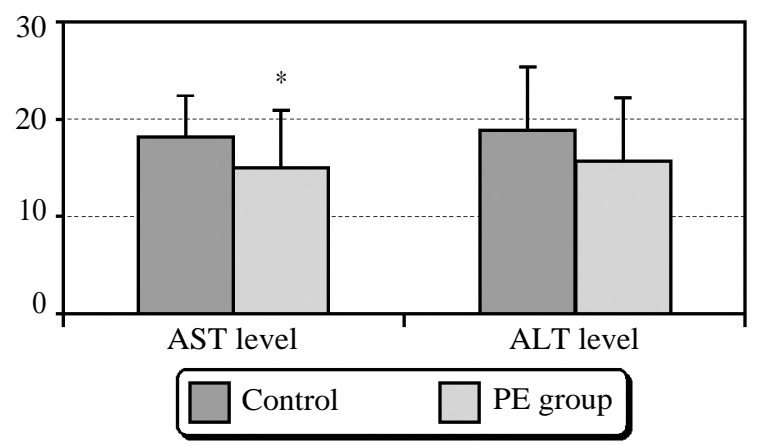

Fig. (5): Comparison between serum AST and ALT levels in the control and PE groups.

Values are mean (in IU/L) \pm SD.

$*$ : Statistically significant differences if $p<0.05$.

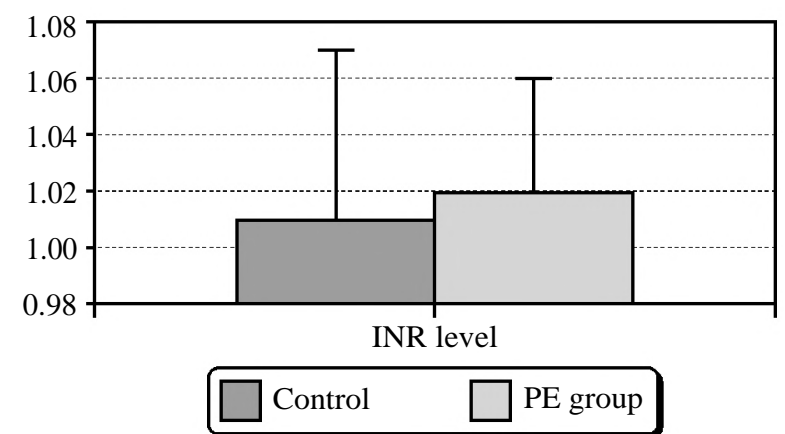

Fig. (7): Comparison between serum INR levels in the control and PE groups.

Values are mean \pm SD.

$*$ : Statistically significant differences if $p<0.05$.

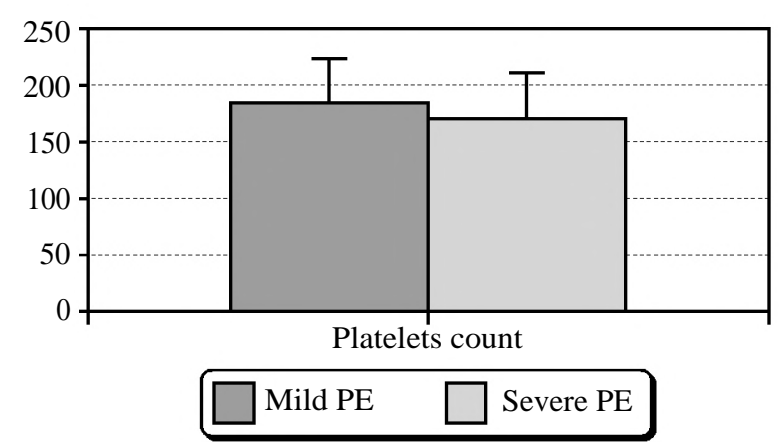

Fig. (9): Comparison between platelets count in the blood of mild and severe cases of PE. 


\section{Discussion}

Pre-Eclampsia (PE) is a disorder of pregnancy characterized by high blood pressure and often a large amount of protein in the urine [23]. PE usually occurs in the 3 rd trimester and worsens over time. Severe forms of PE may be associated with red blood cell breakdown, a low blood platelet count, impaired liver function, kidney dysfunction, swelling, shortness of breath due to fluid in the lungs, or visual disturbances. PE is associated with an increased risk of poor outcomes for both the mother and the baby. If left untreated, it may result in seizures at which point it is known as eclampsia [24].

PE is characterized by abnormal vascular response to placentation associated with increased systemic vascular resistance, enhanced platelet aggregation, activation of the coagulation system and endothelial cell dysfunction [25]. Although PE appears to begin in the placenta, the target organ is the maternal endothelium. Many serum markers of endothelial activation and endothelial dysfunction are deranged in women with pre-eclampsia, including von Willebrand antigen, cellular Fibronectin (FN), soluble tissue factor, soluble Eselectin, platelet-derived growth factor, and endothelin [26].

The current study was a case-control study done on 50 pregnant women attended to inpatient unit of Obstetrics and Gynecology Department, Benisuef University Hospital from March to August 2016. Gestational age was from 31 to 39 as calculated by date of last menstrual period and confirmed by ultrasonographic examination. Women were divided into two groups; the first group included 25 healthy pregnant women and the second group included 25 pre-eclamptic pregnant women (15 mild and 10 severe).

The results of the present study revealed that all participants were homogenous in age and gravidity. As regards serum FN level, it was statistically significantly higher in PE group in comparison with the control group. At the same time, it was statistically significantly higher in cases of severe PE in comparison with cases of mild PE. FN plays a pivotal role in the stability of tissue structure and in the regulation of cell growth and differentiation. FN is a member of a family of high molecular weight extra-cellular matrix glycoproteins and is an adhesive mosaic glycoprotein that has distinct functions, such as the establishment and maintenance of normal cell morphology, cell migration, homeostasis and thrombosis, and wound healing.
Plasma FN is derived primarily from the liver and endothelial cells. As FN is generated in the vascular basement membrane, circulating FN levels may serve as a marker for endothelial damage [27] .

As regards serum Von Willebrand Factor (VWF), it was statistically significantly higher in $\mathrm{PE}$ group in comparison with the control group. On the other hand, there was no statistically significant difference between cases of mild and severe PE regarding serum VWF level. VWF is a large multimeric glycoprotein present in the plasma and produced constitutively as ultra-large VWF in endothelium (in the Weibel-Palade bodies), megakaryocytes ( $(\mathrm{x}$-granules of platelets), and subendothelial connective tissue. The primary function of VWF is binding to other proteins, in particular, factor VIII, and it is also important in platelet adhesion to wound sites. It is not an enzyme and thus, has no catalytic activity [28]. VWF binds to exposed subendothelial collagen due to damage occurring to the blood vessel. VWF is also released from endothelium which forms additional links between the platelets glycoprotein Ib/IX/V and the collagen fibrils. VWF also binds to platelet glycoprotein Ib when it forms a complex with glycoproteins IX and V; this binding occurs under all circumstances but is most efficient under high shear stress as a result of rapid blood flow in narrow blood vessels [29]. As VWF is generated in the vascular basement membrane, circulating VWF levels may serve as a marker for endothelial damage in pre-eclampsia.

As regards platelets count, it was statistically significantly lower in PE group in comparison with the control group. At the same time, there was no statistically significant difference between cases of mild and severe PE regarding platelets count. Although the pathogenesis of thrombocytopenia in PE is not clear, it is suggested that it may be due to endothelial damage and peripheral consumption. The lifespan of platelet reduced to 3-5 days and the altered platelet membrane accelerates its aggregation and destruction [30] .

It also can be explained by that platelet activation is a major cause of accelerated platelet clearance in this disorder and this argument is supported by increased plasma levels of the platelet a-granule proteins 0 -thromboglobulin and platelet factor 4 , as well as the increased levels of thromboxane A2 metabolites in the urine of pre-eclamptic patients. The activation of the coagulation system and generation of thrombin leads to platelets activation with an accelerated clearance of activated platelets. The platelets contact with exposed subendothelium 
underlying the injured placental vasculature, increased level of VWF, as well as adhesive proteins such as FN also cause platelet activation. Patients with PE also display micro-angiopathic hemolytic anemia due to red cell fragmentation, due to shearing of red cells on fibrin strands in the microvasculature or placental circulation [31] .

In conclusion, the present study shows that serum FN, VWF levels and platelets count can be used as markers of endothelial and platelet dysfunction in PE and play a role in confirming the diagnosis. Serum FN level can be also used to determine the severity of PE.

\section{References}

1- BDOLAH Y., KARUMANCHI S.A. and BENJAMIN P. SACHS: Recent advances in understanding of preeclampsia. Croatian Medical Journal, 46 (5): 728-36, 2005.

2- STEEGERS E.A., VON DADELSZEN P., DUVEKOT J.J. and PIJNENBORG R.: Pre-eclampsia. Lancet, 376 (9741): 631-44, 2010.

3- DUCKITT K. and HARRINGTON D.: Risk factors for preeclampsia at antenatal booking: Systemic review of controlled studies. B.M.J., 330: 565, 2005.

4- ARULKUMARAN N. and LIGHTSTONE L.: "Severe pre-eclampsia and hypertensive crises". Best Practice \& Research Clinical Obstetrics \& Gynaecology, 27 (6): 877 84, 2013.

5- MUSTAFA R., AHMED S., GUPTA A. and VENUTO R.C.: A comprehensive review of hypertension in pregnancy. Journal of Pregnancy, 2012.

6- CUNNINGHAM F.G., LEVENO K.J., BLOOM S.L., HAUTH J.C. and GILSTRAP L.C.: Wenstrom KD. Williams's obstetrics. 22 nd ed. Philadelphia: WB Saunders. 608-837. Omit, 2005.

7- MILNE F., REDMAN C., WALKER J., BAKER P., BRADLEY J., COOPER C., De SWIET M., FLETCHER G., JOKINEN M., MURPHY D. and NELSON-PIERCY C.: The Pre-Eclampsia Community Guideline (PRECOG): How to screen for and detect onset of pre-eclampsia in the community. B.M.J., 330 (7491): 576-80, 2005.

8- National Institute for Health and Care Excellence (NICE): Hypertension in pregnancy: the management of hypertensive disorders during pregnancy. NICE CG 107. Manchester, UK: National Institute for Health and Clinical Excellence, 2010

9- CONDE-AGUDELO A.G., ROMERO R.O. and LINDHEIMER M.D.: Tests to predict preeclampsia. Chesley's hypertensive disorders in pregnancy. Amsterdam: Academic Press, Elsevier, 16: 189-211, 2009.

10- ROBERTS J.M., TAYLOR R.N. and GOLDFIEN A. Clinical and biochemical evidence of endothelial cell dysfunction in the pregnancy syndrome preeclampsia. American Journal of Hypertension, 4 (8): 700-8, 1991.

11- SHAARAWY M. and EL-DIDY H.: Thrombomodulin, plasminogen activator inhibitor type 1 (PAI-1) and fibronectin as biomarkers of endothelial damage in preec- lampsia and eclampsia. International Journal of Gynecology \& Obstetrics, 55 (2): 135-9, 1996.

12- SZARKA A., RIGÓ J., LÁZÁR L., BEKO G. and MOLVAREC A.: Circulating cytokines, chemokines and adhesion molecules in normal pregnancy and preeclampsia determined by multiplex suspension array. B.M.C. immunology, 11 (1): 59, 2010.

13- GEORGE E.L., GEORGES-LABOUESSE E.N., PATELKING R.S., RAYBURN H. and HYNES R.O.: Defects in mesoderm, neural tube and vascular development in mouse embryos lacking fibronectin. Development, 119: 1079-91, 1993.

14-PANKOV R. and YAMADA K.M.: Fibronectin at a glance. Journal of Cell Sci., 20 (115): 3861-3, 2002.

15- WILLIAMS C.M., ENGLER A.J., SLONE R.D., GALANTE L.L. and SCHWARZ-BAUER J.E.: Fibronectin expression modulates mam-mary epithelial cell proliferation during acinar differentiation. Cancer Research, 9 (68): 3185-8192, 2008

16- American College of Obstetricians and Gynecologists. Hypertension in pregnancy: Report of the American College of Obstetricians and Gynecologists' task force on hypertension in pregnancy. Obstetrics and Gynecology, 122 (5): 1122, 2013

17- THAVASU P.W., LONGHURST S., JOEL S.P., SLEVIN M.L. and BALKWILL F.R.: Measuring cytokine levels in blood: Importance of anticoagulants, processing, and storage conditions. Journal of Immunological Methods, 153 (1-2): 115-24, 1992

18- JONES A.R., TWEDT D., SWAIM W. and GOTTFRIED E.: Diurnal change of blood count analytes in normal subjects. American Journal of Clinical Pathology, 106 (6): 723-7, 1996.

19- Beckman Synchron LX Systems Chemistry Information Manual, 2001.

20- Beckman Coulter Synchron Clinical Systems Chemistry Information Manual, 2007.

21- QUICK A.J.:Bleeding problems in clinical medicine. WB Saunders Company, 1970.

22- CHAN Y.H.: Biostatistics 102: Quantitative DataParametric \& Non-parametric Tests. Singapore Med. J., 44 (8): 391-6, 2003.

23- CHAN Y.H.: Biostatistics 104: Correlational Analysis. Singapore Med. J., 44 (12): 614-9, 2003.

24- EILAND E., CHIKE N. and MARQUETTA F.: "Preeclampsia 2012". J. of Pregnancy, 1-7, 2012.

25- AL-JAMEIL N., AZIZ KHAN F., FAREED KHAN M. and TABASSUM H.: "A brief overview of preeclampsia." Journal of Clinical Medicine Research, 6 (1): 1-7, 2014.

26- SIBAI B., DEKKER G. and KUPFERMINC M.: Preeclampsia. The Lancet, 365 (9461): 785-99, 2005.

27- VENKATESHA S., TOPORSIAN M., LAM C., HANAI J.I., MAMMOTO T., KIM Y.M., BDOLAH Y., LIM K.H., YUAN H.T., LIBERMANN T.A. and STILLMAN I.E. Soluble endoglin contributes to the pathogenesis of preeclampsia. Nature Medicine, 12 (6): 642-9, 2006.

28- BLUM A., SHENHAV M., BARUCH R. and HOFFMAN M.: Endothelial dysfunction in pre-eclampsia and eclamp- 
sia: Current etiology and future non-Invasive assessment. IMAJ, 5: 724-6, 2003.

29- SADLER J.E.: Biochemistry and genetics of von Willebrand factor. Annual review of biochemistry, 67 (1): 395424, 1998

30- RANDI A.M. and LAFFAN M.A.: Von Willebrand factor and angiogenesis: Basic and applied issues. Journal of Thrombosis and Haemostasis, 2016.
31- SARKAR P.D. and SOGANI S.: Association of antithrombin-III and platelet count with pregnancy induced hypertension. International Journal of Reproduction, Contraception, Obstetrics and Gynecology, 2 (3): 398401, 2016.

32- McCRAE K.R.: Thrombocytopenia in Pregnancy. 2 nd edition. In: Michelson A.D. (ed.).Platelets. London: Elsevier: 928-30, 2007.

\section{الخلل الوظيفى للجدار المبطن للآوعية الدموية والصفائح الدموية

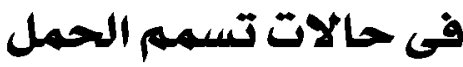

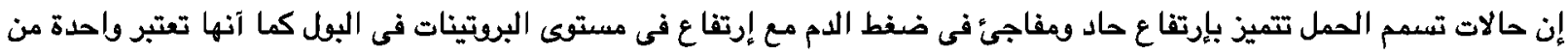

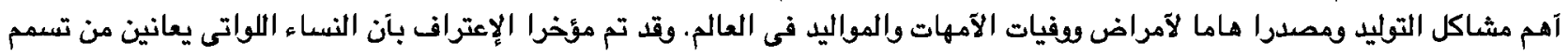

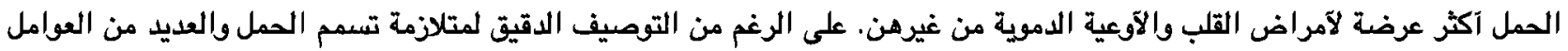

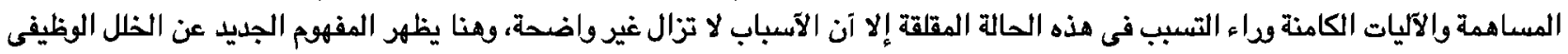

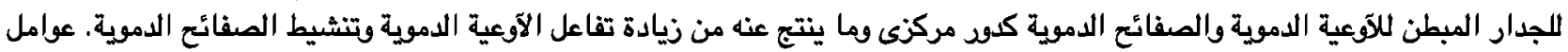

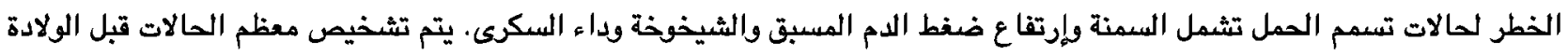
ونادرا ما تبدآ حالات تسمم الحمل بعد الولادة.

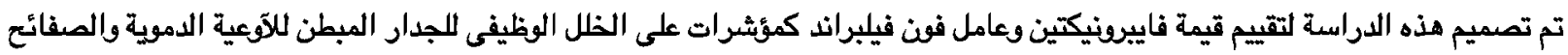

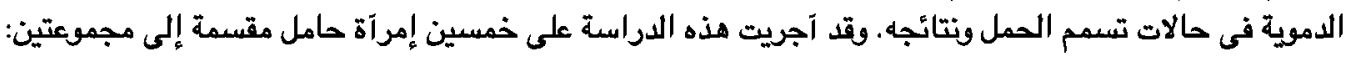
ا- المجموعة الآولى : شملت خمس وعشرين إمرآة تم تشخيصهن بتسمم الحمل (مجموعة الدراسة). ا- المجموعة الثانية: شملت خمس وعثرين إمرآة حامل صدية (مجموعة هراقبة).

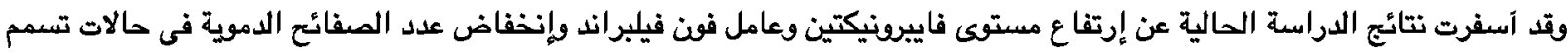

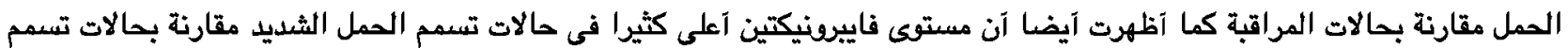

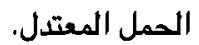

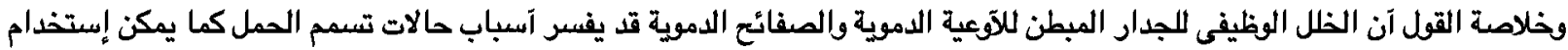

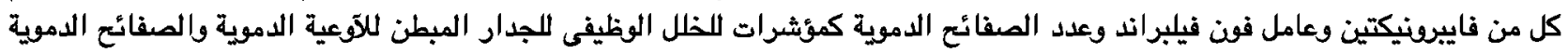

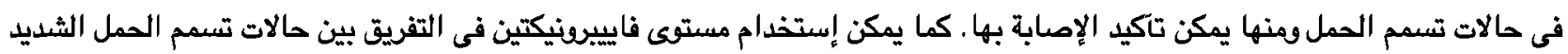

